MUZIKOLOŠKI ZBORNIK - MUSICOLOGICAL ANNUAL XL

UDK 783(497.4)"18"

Aleš Nagode

Philosophische Fakultät, Universität in Ljubljana

Filozofska fakulteta Univerze v Ljubljani

\title{
Die Rolle des mitteleuropäischen Raumes in der Entwicklung der slowenischen Kirchenmusik des 19. Jahrhunderts
}

\author{
Vloga Srednje Evrope v razvoju slovenske \\ cerkvene glasbe 19. stoletja
}

ZUSAMMENFASSUNG

Die slowenische Kirchenmusik war - aus spezifischen kultur-historischen Gründen - wahrscheinlich der einprägendste Anzeiger der Eingebundenheit der slowenischen Musik in die europäischen und damit mitteleuropäischen Strömungen. Nach Slowenien kamen sie durch die Vermittlung fremder Musiker, teilweise aber auch mittels der Slowenen, die sich in der Fremde ausbildeten und künstlerisch formten. Erste Anzeichen des Zuflußes neuer Ansichten über die Kirchenmusik war die Durchsetzung des Historismus'. Die ersten Spuren davon finden wir in den Schriften von Kamilo Mašek. In seiner Zeitung Cäcilia machte er auf die Bedeutung von Palestrina und den einheimischen Gallus aufmerksam, mit seiner zurückhaltenden Einstellung gegenüber den Kirchenwerken von Haydn und Mozart war er einer der ersten Verkünder der neuen historistischen Ästhetik.

Das neue Ideal der Kirchenmusik drang allmählich in die Musikpraxis dort vor, wo die Befähigung der ausführenden Kräfte dies erlaubte, z.B. in der Domkirche in Ljubljana in der zweiten Hälfte der fünfziger und am Anfang der sechziger Jahre. Hier gewann es die Vorherrschaft erst nach dem Jahre 1868, als die Leitung des Domchores der tschechische Musiker Anton Foerster übernahm. Weniger beeinflußte der Historismus in Slowenien das kompositorische
POVZETEK

Slovenska cerkvena glasba je bila - zaradi specifičnih kulturnozgodovinskih okoliščin - verjetno najbolj izrazit kazalec vpetosti slovenske glasbe $\mathrm{v}$ evropske in $\mathrm{z}$ njimi srednjeevropske tokove. Ti so na Slovensko prihajali s posredovanjem tujih glasbenikov, deloma pa tudi s Slovenci, ki so se izobraževali in umetniško izoblikovali v tujini. Prvi znak pritekanja sodobnih nazorov o cerkveni glasbi je bilo uveljavljanje historizma. Njegove sledove zasledimo prvič v spisih Kamila Maška. S svojim časopisom Cäcilia je opozoril na pomen Palestrine in domačina Gallusa ter postal z zadržanim odnosom do cerkvenih skladb Haydna in Mozarta eden prvih znanilcev nove historistične estetike. Novi ideal cerkvene glasbe je postopno prodiral tudi v glasbeno prakso tam, kjer je usposobljenost izvajalskih moči to dopuščala, npr. v ljubljanski stolnici v drugi polovici petdesetih in v začetku šestdesetih let. Tu je prevlado dosegel šele po letu 1868, ko je vodenje stolnega kora prevzel češki glasbenik Anton Foerster. Manj je historizem na Slovenskem vplival na skladateljsko delo tega časa. Zasledimo lahko le redke in kompozicijsko prešibke poskuse.

Uveljavljanje novih estetskih idealov v slovenski cerkveni glasbe je naletelo - glede na evropske razmere - na nenavaden položaj. Ob vsesplošnem občutku nacionalne ogroženosti, ki je preveval 
Schaffen dieser Epoche, zu vermerken sind nur einzelne und kompositorisch zu schwache Versuche. Die Durchsetzung neuer ästhetischer Ideale in der slowenischen Kirchenmusik stieß - mit Rücksicht auf die europäischen Verhältnisse - auf eine ungewöhliche Situation. Angesichts des allgemeinen Gefühls des Bedrohtseins, von welchem die slowenische Intelligenz durchdrungen war, wurde in der slowenischen Öffentlichkeit jede Neuheit als ein Angriff auf die nationale Identität empfunden. Die Versuche der leitenden Kirchenmusiker, das historistische Repertoire durchzusetzen und die populären slowenische Kirchenlieder vom Anfang es 19. Jahrhunderts durch dieses zu ersetzen, stießen auf Widerspruch beider politischer Lager, so des liberalen, wie des konservativen. Die Gegner der neuen Musik - die vor allem ihre Fremdheit angriffen - übersahen die Tatsache, daß auch das populäre slowenische mehrstimmige Kirchenlied auf musikalischen Elementen aufgebaut ist, die national nicht gekennzeichnet waren, sondern allgemein im ostalpenländischen Raum verbreitet waren. Der große Zwist über die echte slowenische Kirchenmusik entlhüllt sich deswegen eher als ein Konflikt zwischen dem Alten und dem Neuen, als zwischen dem Einheimischen und dem Fremden. Offensichtlich ist auch die Tatsache, daß die slowenische Kirchenmusik im 19. Jahrhundert - die alte und die neue - zwar eng mit den übrigen österreichischen und süddeutschen Ländern verbunden war, keinesfalls aber kann von einer Verbundeheit mit ganz Mitteleuropa die Rede sein. slovensko izobraženstvo, je bila vsaka novost v slovenski javnosti občutena kot napad na nacionalno identiteto. Poskusi vodilnih cerkvenih glasbenikov, da bi uveljavili historistični repertoar in z njim nadomestili popularne slovenske cerkvene pesmi iz začetka 19. stoletja, so naleteli na odpor obeh političnih taborov, tako liberalnega kot konservativnega. Nasprotniki nove glasbe - ki so napadali predvsem njeno tujost - so spregledali dejstvo, da je bila tudi popularna slovenska cerkvena pesem grajena z glasbenimi prvinami, ki niso bile nacionalno zaznamovane, temveč so bile splošno razširjene $\mathrm{v}$ vzhodnoalpskem prostoru. Veliki spor o pravi slovenski cerkveni glasbi se zato izkaže prej kot konflikt med starim in novim, kot med domačim in tujim. Hkrati pa kaže, da je bila slovenska cerkvena glasba 19. stoletja - stara in nova - sicer res tesno povezana $\mathrm{z}$ ostalimi avstrijskimi in južnonemškimi deželami, nikakor pa ne moremo govoriti o povezanosti s celo Srednjo Evropo.

Die Beschäftigung mit der Kirchenmusik des 19. Jahrhunderts scheint auf ersten Blick uninteressant zu sein. Schon ein flüchtiger Überblick der musikgeschichtlichen Lietratur bekräftigt unsere Überzeugung, daß die Forschung dieser Gattung heute mehr oder weniger im Randbereich der Musikwissenschaft wahrzunehmen ist. Dieser Zustand ist auf die Tatsache zurückzuführen, dass die Kirchenmusik seit Mitte des 18. Jahrhunderts unaufhaltbar ihre zentrale Rolle in der Kunst der Musik verloren hat. Ihre Funktion und ästhetische Unterstellung den kirchlichen Riten führte zu immer größeren Widersprüchen mit den Entwicklungstendenzen der zeitgenössischen $\mathrm{Mu}$ sik. Auf anderer Seite öffnete das auflebende bürgerliche Musikleben den fähigeren Komponisten neue und einträglichere Wege zum Erwerb gerade in einer Zeit, in welcher die wachsende Säkularisierung den Einfluß und die ökonomische Kraft der Kirche stark ins Wanken brachte. Das Komponieren und Ausführen von Kirchenmusik wurde immer mehr zur Sache jener, die sich in der großen Welt der Oper und des Konzertes nicht bewähren konnten. Die wenigen kirchenmusikalischen Werke großer Meister des 19. Jahrhunderts, die auch heute noch immer im Interesse der Musikwissenschaft stehen, verdanken diese Aufmerksamkeit vor allem der Tatsache, daß sie zur Zeit ihrer 
Entstehung nicht den zeitgenössischen Ansichten über angemessene Kirchenmusik entsprachen, und können deswegen als Teil des heutigen Konzertrepertoires weiter existieren.

Wenn also die Beschäftigung mit der Kirchenmusik für die allgemeine Musikgeschichte weniger interessant ist, ist sie jedoch für die Forschung einiger marginaler nationaler musikalischer Kulturen, zu welchen auch die slowenische gehörte, nötig. Die kirchliche musikalische Produktion in Slowenien entwickelte sich im Vergleich mit anderen Musikgattungen aus politischen und kulturellen Gründen nicht verhältnismäßig. In einer Umwelt, in welcher aus verschiedenen Gründen die deutsche Sprache überwiegend im Gebrauch war, war oft die Kirche der einzige Ort, an welchem die slowenische Sprache zur öffentlichen Geltung kam. So ist es verständlich, daß das slowenische mehrstimmige Kirchenlied in der Mitte des 19. Jahrhunderts, also in einer Zeit, in welcher sich die weltliche vokale Musik in slowenischer Sprache nur allmählich und mit Schwierigkeiten ihre ersten Wege auf die Konzert- und Opernbühne bahnte, schon Jahrhunderte lang ein eingebürgerter Teil des Gottesdienstes war. So ist in Slowenien eben die Kirchenmusik diese Sparte des musikalischen Schaffens, in welcher wir durch den überwiegenden Teil des 19. Jahrhunderts am unmittelbarsten die Beziehung zwischen dem slowenischen und dem mitteleuropäischen Raum betrachten können.

Der Ausgangspunkt der Entwicklung der slowenischen Musik im 19. Jahrhundert sind die Verhältnisse nach der Epoche der Josephinischen Reformen und der Napoleonkriege, die in den letzten Jahrzehnten des 18. und am Anfang des 19. Jahrhunderts die organisatorischen und ökonomischen Fundamente der kirchlichen Institutionen ins Wanken brachten, die aber auch entschieden das Niveau der Ausführungen der Kirchenmusik beeinflußten. Auffallend ist der große Qualitätsunterschied der Kirchenmusik in den Städten und in ländlichen Pfarren. In den Städten wurde neben dem täglichen Singen deutscher und slowenischer Kirchenlieder, im größeren oder kleineren Umfang, auch die Tradition der regelmäßigen Ausführungen vokal instrumentaler kirchlicher Werke auf lateinische Texte gepflegt. Das Repertoire war ausgesprochen "mitteleuropäisch". Es bestand aus Werken von Komponisten der Wiener Klassik, ihrer Zeitgenossen und Nachfolger (Joseph und Michael Haydn, Wolfgang A. Mozart, Ludwig van Beethoven, Anton Diabelli, Johann Nepomuk Hummel, Joseph Eybler, Carl Czerny, Johann Baptist Schiedermayer u.a.). Das Repertoire wurde in beträchtlichem Maße von Werken auf slowenischem Gebiet lebender Komponisten erweitert, wie z.B. František Benedikt Dussik, Karl Venceslav Wratny, Leopold Ferdinand Schwerdt, Anton Höller, Josef Miksch u.a.

Dementgegen hat sich die slowenische Kirchenmusik auf dem Lande bis zur Mitte des 19. Jahrhunderts kaum geändert und blieb meistens auf dem Niveau der vorjosephinischen Zeiten. Das Musikrepertoire bestand aus Werken, die aus verschiedenen Quellen von musikalisch nur schlecht ausgebildeten Dorforganisten angeschafft wurden. Melodien und Texte wurden oft von ihnen selbst geschrieben, oder es wurden für neue slowenische Texte Weisen aus zeitgenössischen deutschen und älteren slowenischen Kirchenliederbüchern umgearbeitet. Nicht selten langte man auch nach Weisen bekannter Volkslieder und anderer populärer Gesänge. ${ }^{1}$ Das derart geformte Repertoire siedelte zusammen mit dem Organisten von Pfarre zur Pfarre, ${ }^{2}$ allmählich 
führte das zu einem Ausgleich des musikalischen Geschmacks in slowenischen Landen. Die Ausführungskräfte wurden an bedeutenderen Gelegenheiten mit Volksmusikanten ergänzt, die an Feiertagen und bei besonderen Feierlichkeiten in die Dorfkirchen wenigstens eine Spur jener barocken Repräsentativität brachten, die bis zur zweiten Hälfte des 19. Jahrhunderts im Geschmack des Volkes als Ideal des Kirchenritus blieb. ${ }^{3}$ Ihr Beitrag waren ein Marsch beim Introitus, ein Walzer, eine Polka oder Mazurka während des Gottesdienstes und obligat ein Trommelwirbel bei der Erhebung der Hostie. ${ }^{4}$

Dieser Zustand, der im hohen Maße auf den Mangel eines entsprechenden künstlichen, jedoch von der ländlichen Bevölkerung ausführbaren Repertoires zurückzuführen ist, rief in gebildeten Kreisen immer wieder Entrüstung hervor. Trotz zahlreicher prinzipieller Erörterungen, wie diese Verhältnisse zu verbessern, blieb es nur bei wenigen sachlicher Maßnahmen. Den größten Erfolg hatte der Versuch des Domvikars und Organisten Gregor Rihar in Ljubljana, der zusammen mit dem Textautor Blaž Potočnik in den vierziger und fünfziger Jahren mehrere Sammlungen slowenischer mehrstimmiger Kirchenlieder herausgab. So versahen beide Autoren die Dorfkirchen mit einem musikalisch entsprechenderem und vor allem dogmatisch einwandfreiem Repertoire für verschiedene Anlässe im Laufe des Kirchenjahres. Diese Kompositionen wurden mit Begeisterung empfangen. Sie wurden vom bischöflichen Ordinariat unterstützt und waren bei der Geistlichkeit, den Kirchensängern und den Gläubigen, sehr beliebt. Die Melodien der Lieder von Rihar wurden schnell volkstümlich, beide Autoren wurden als Gründer der slowenischen Musik gefeiert. Nur wenig Bedeutung hatten dabei weder der etwas schwächere harmonische Satz, noch die zu sehr nach völkischem Geschmack gerichteten Melodien. Die Anekdote, nach welcher Rihar nach den Opernvorstellungen oft voller Inspiration nach Hause eilte, um eine gefällige Melodie aufs Papier zu bringen, ist nämlich nicht weit von der Wahrheit.

Zeitgenössischere Ansichten über die stilistische Gestaltung der Kirchenmusik, vorerst der Historismus, später als seine reifere Realisation, die Cäcilianische Bewegung, setzten sich in Slowenien erst in der Mitte des 19. Jahrhunderts durch. Die Träger dieser Bewegung waren vor allem fremde Musiker aus mitteleuropäischen Ländern, die auf slowenischem Boden ihren Erwerb suchten, teilweise aber auch Slowenen, die in der Fremde studiert haben. Die ersten Spuren der Durchsetzung historischer Ansichten in der Kirchenmusik sind in den Schriften und Kompositionen von Kamilo Mašek, der in den Jahren von 1850 bis 1852 in Wien studiert hatte, zu finden. In seiner Zeitung Cäcilia veröffentlichte er im Jahre 1857 eine Reihe von Biografien berühmter Komponisten der Vergangenheit. Die Auswahl der Persönlichkeiten und die Bewertung ihrer Beiträge zur Entwicklung der Kirchenmusik zeigen deutlich darauf hin, daß er zur

\footnotetext{
${ }^{1}$ Ein besonders drastischer Fall unter vielen war ein Marienlied auf die Melodie "Unsere Katze hatte Junge». Vgl. Ferdinand Vigele, "O cerkveni glasbi“ [Über die Kirchenmusik], in: Učiteljski tovariš [Der Genosse des Lehrers] 8 (1868), Nr. 8 , Seite 121-124.

2 Anton M. Slomšek, "Cerkveno petje nekdanjo in sedanjo po Štajerskem" [Der einstige und jetzige Kirchengesang in der Steiermark], in: Drobtinice [Krümelchen] 12 (1857), Seite 216, 293; 298-9.

3 Franc Kosar, "V zadevi nove slovenske pesmarice" [In Sache eines neuen slowenischen Liederheftes], in: Zgodnja Danica [Der frühe Morgenstern] 3 (1850), Nr. 52, Seite 217.

4 "Gregor Rihar", in: Drobtinice 22 (1888), Seite 91-118.
} 
Zeit seines Aufenthaltes in der Fremde, historistische Ansichten und Werturteile annahm. Den Vorrang unter den Kirchenkomponisten schrieb er Palestrina zu, den er auch als den "König der Kirchenmusik" benannte, neben ihm wurden aus dem 16. und 17. Jahrhundert noch drei Komponisten angeführt: Jacobus Gallus, Orlando di Lasso und Grigorio Allegri. ${ }^{5}$ Andererseits offenbart sich in den Biografien der großen Komponisten der zweiten Hälfte des 18. Jahrhunderts - neben der Betonung ihres Beitrages anderen Musikgattungen z.B. der sinfonischen oder der Kammermusik - eine ausgesprochene Zurückhaltung gegenüber ihrem kirchenmusikalischen Werk, als hochwertige werden nur die Kompositionen hervorgehoben, denen auch die deutsche historisch orientierte Publizistik der ersten Hälfte des 19. Jahrhunderts den Rang einer wahren Kirchenmusik anerkannte. So werden in der Biografie von Joseph Haydn ${ }^{6}$ seine großen und zu dieser Zeit in Slowenien noch immer höchst populären Messen kaum erwähnt, von den Messen Mozarts nur das Requiem. ${ }^{7}$ Mit Begeisterung wird dagegen die ernstere Kirchenmusik von Michael Haydn empfohlen. ${ }^{8}$ Am deutlichsten zeigen sich die historistischen Ansichten von Mašek in der biografischen Abhandlung Jacobus Gallus im Sammelwerk Vodnikov spomenik aus dem Jahre 1859. Im Artikel wird zweifelsohne hervorgehoben, daß die Werke von Palestrina und Gallus den Höhepunkt der Kirchenmusik aller Zeiten bedeuten. Indirekt wird auch angedeutet, dass die zeitgenössischen Komponisten den alten nicht ebenbürtig sein können. In einer Bemerkung in Verbindung einiger Bearbeitungen der Kompositionen von Gallus, die in der Leipziger Zeitung Allgemeine Musikzeitschrift erschienen sind, macht er die Arrangeure darauf aufmerksam, daß alle zeitgenössischen Zuschneider klassischer Werke nicht einen Gallus ersetzen können.?

Die historistischen Ansichten sind schnell in die Musikpraxis der zentralen städtischen Kirchen eingedrungen. Das klassizistische kirchliche Musikrepertoire auf lateinische Texte wich allmählich, vorerst nur an ausgesuchten Gelegenheiten, dem historistischen. Der Domchor erwarb in der zweite Hälfte der fünfziger Jahre zumindest einige Hefte fundamentaler deutscher historistischer Editionen, z.B. die Sammlungen Musica Divina und Selectus novus missarum von Karl Proske. ${ }^{10}$ Die neuen Musikalien wurden durchaus nicht für Studienzwecke angeworben, neben den Partituren wurden auch die für die Ausführung nötigen Stimmen beschafft. Im Jahre 1857 beteuert Mašek, daß sich jedermann von der Schönheit und der Wirkung des Misere-

\footnotetext{
Cäcilia 1 (1857), Nr. 7, Seite 52; Cäcilia 1 (1857), Nr. 5, Seite 34; Cäcilia 1 (1857), Nr. 16, Seite 121.

Cäcilia 2 (1858), Nr. 1, Seite 7.

Cäcilia 2, (1858), Nr. 3, Seite 29.a

8 "Im Kirchenstyle war er einer der trefflichsten Componisten." Vgl. Cäcilia 2 (1858), Nr. 3 Seite 29.

9 Kamilo Mašek, "Jacobus Gallus", in: Vodnikov spomenik [Vodnik's Denkmal], Ljubljana 1859, Seite 177-178.

${ }^{10}$ Janez Zlatoust Pogačar, "Über Kirchenmusik“, in: Triglav 4 (1869), Nr. 60, Seite 4-6. Seine Anführung, daß Gregor Rihar für den Domchor fünf Hefte der Editionen von Proske gekauft hätte, stimmt nich in Gänze. Die Inventaraufnahme der Musikalien des Domchores aus dem Jahre 1864 (ein Jahr nach Rihar's Tod) enthält nur das 1. und 2. Heft der Sammlung Musica Divina von Proske, die schon 1853 bzw. 1855 erschien. Möglich aber ist, daß das 3. und 4. Heft der Sammlung Musica Divina und das 1. Heft der Sammlung Selectus novus missarum zwischen den Jahren 1864 und 1868 gekauft wurden, man kann sie noch heute unter den erhaltenen Musikalien des alten Domarchivs finden. Vgl. Viktor Steska, "Glasbeni inventar stolnega kora v Ljubljani pod Gregorjem Riharjem", [Das musikalische Inventar des Domchores in Ljubljana unter Gregor Rihar], in: Cerkveni glasbenik [Der Kirchenmusiker] 51 (1928), Seite 113-119. Venčeslav Snoj und Alojzij Mav, "Inventarni popis starega stolnega arhiva" [Die Inventaraufnahme des alten Domarchives], Handschrift, Archiv des Domchores in Ljubljana.
} 
re von Palestrina bei den Gottesdiensten in der Karwoche im Dom in Ljubljana überzeugen kann - in der Ausführung des Chores der Theologiestudenten, freilich unter der Leitung des regens chori Gregor Rihar. ${ }^{11}$ Daß diese Ausführungen großen Erfolg bei den Hörern hatten, erinnert sich Josip Levičnik, der berichtet, daß während der Gottesdienste am Karfreitag - die ansonsten nicht zu den beliebtesten österlichen Zeremonien zählten - vor dem Dom in Ljubljana eine lange Reihe von Droschken stand, wie zu großen Feiertagen. ${ }^{12}$ Die neuen Ideale reichten aus Ljubljana auch in andere Gegenden. Kamilo Mašek gewann für die Idee seinen Schüler Anton Hribar, der später in Vipava (zwischen den Jahren 1859 und 1861) und Gorizia, historistische musikalische Kirchenwerke ausführte. ${ }^{13}$

Schwächer war das Echo der zeitgenössischen Ansichten in der Kirchenmusik auf slowenische Texte. In das geistige Umfeld des Historismus' können nur die Kirchenlieder von Mašek eingereiht werden, die er in der Revue Cäcilia im Jahre 1858 veröffentlicht hatte. Mit diesen wirklich einfachen Kompositionen, die vor allem unerfahrenen Ausführenden vom Lande zugedacht waren, wünschte er ein Repertoire zu schaffen, welches die für die Kirche unangemessenen Erzeugnisse der Dorfmusikanten und angelernter Organisten, die in dieser Zeit auf slowenischen Chören noch immer überwiegend im Gebrauch waren, zu verdrängen. Die einfache homofone und homorhythmische Faktur, frei jegliche Expressivität, war vielleicht ein, in kleinem Umfang realisiertes Ideal der "edlen Einfalt", welche die Fürsprecher des neuen kirchenmusikalischen Stils in den Werken von Palestrina erkannten. Mit seinen Bemühungen hatte Mašek nur wenig Erfolg, bald warf man ihm vor, daß seine Werke auf "fremden" Ideen gegründet seien, die in Slowenien keinen Erfolg haben werden. ${ }^{14}$ Mögliche ehrgeizigere Pläne wurden durch den zu frühen Tod von Mašek im Jahre 1859 vereitelt.

Die Bemühungen um die Durchsetzung zeitgenössischer Ansichten in der Kirchenmusik wurden von seinem Nachfolger als Lehrer an der Öffentlichen Musikschule, Anton Nedvd, weitergeführt. Dieser, zwar in der Tschechei geborene und bei Professoren am Prager Konservatorium ausgebildete Musiker, machte beim Unterricht zukünftiger Lehrer, die damals auch den Dienst der Organisten versahen, mit rauen Worten auf die Unangemessenheit der für den zeitgenössischen Geschmack all zu sehr sekulärer und kompositions-technisch schwacher Kompositionen von Rihar aufmerksam. Über die Kompositionen von Rihar sollte er noch vor dem Jahre 1862 beim Unterricht gesagt haben: "Diesem Elende in Krain muß ein Ende gemacht werden! ${ }^{15}$ Zur entgültigen Verschärfung kam es anlässlich seines Versuchs im Jahre 1865, beim Singen der Abendandachten im Dom in Ljubljana die traditionellen vierstimmigen Antifonen und Hymnuse von Rihar mit einem unisono (vermutlich einem choralen) Gesang zu ersetzen. Der Vorfall erhielt nationale Dimensionen, auch die Tages-

\footnotetext{
${ }^{11}$ Cäcilia 1 (1857) 7, 52.

${ }^{12}$ Jožef Levičnik, "Gregor Rihar", in: Koledarček družbe sv. Mohorja za leto 1865 [Kalender des Sankt Hermagoras' Vereins für das Jahr 1865], Seite 33-40.

${ }^{13}$ Wilhelm Urbas, "Camilo Maschek. Eine biografische Skizze", in: Mittheilungen des historischen Vereins für Krain (1861), Seite 75-79.

${ }^{14}$ Jožef Levičnik, "Beseda o slovenskih pesmih in napevih" [Ein Wort über die slowenischen Kirchenlieder und Gesänge], in: Zgodnja Danica 15 (1862), Nr. 11, Seite 86-87.

${ }^{15}$ Slovenec [Der Slowene] 1 (1865), Seite 99.
} 
zeitungen reagierten scharf. Der Klagenfurter Slovenec bezeichnete Nedved erniedrigend als "einen Lehrer aus Ljubljana", der sich erdreistet in die Erbschaft des großen Rihar einzugreifen. Die Zeitung Novice nannten seinen Versuch "eine kolossale Frechheit ${ }^{16}{ }^{16}$ Dieses Echo erschütterte Nedvd jedoch nicht, die Presse reagierte drei Jahre später wieder auf seine pädagogische Arbeit. Der Redakteur des Učiteljski tovariš, Andrej Praprotnik, hatte in Sinn eben ihn, als er niederschrieb, daß [...] an den Präparanduren fremde kulturtragende Gelehrte den einzigartig schönen slowenischen Gesang unterdrücken." ${ }^{17}$

Einen neuen Aufschwung bekam die Durchsetzung der zeitgenössischen Ansichten in der Kirchenmusik mit dem Aufleben der Cäcilianischen Bewegung in Deutschland Ende der sechziger Jahre. Der erste Widerhall in Slowenien war ein Rundschreiben aus dem Jahre $1868,{ }^{18}$ in welchem der Plan der Reform der Kirchenmusik im Dom in Ljubljana dargelegt wurde. Obwohl das Zirkular vom Dompropst Janez Z. Pogačar unterschrieben war, scheint die Vermutung, daß der Plan in Gänze vom neuen regens chori, Anton Foerster, verfaßt wurde, angebracht zu sein. Dieser Komponist und Musiker, ein Abkomme einer angesehenen tschechischen Musikerfamilie, den neben einer gründlichen musikalischen Ausbildung auch eine außerordentliche Frommheit auszeichnete, begründete die Erneuerung der Kirchenmusik im Dom in Ljubljana in Gänze auf Cäcilianischen Idealen. Die alte vokal-instrumentale Musik sollte der nur vokalen weichen, die spärlichen Besetzungen der Singstimmen dem zeitgenössischen Chorklang. Die oberen Singstimmen sollten von Knaben gesungen werden.

Obwohl der vorgestellte Plan in organisatorischen Sinn nicht realisiert wurde, begann Foerster mit einer allmählichen Erneuerung des ausgeführten Repertoires. Aus seinem Bericht über die Tätigkeit des Domchores in der zentralen deutschen cäcilianischen Revue Musica sacra im Jahre 1876 ist zu entnehmen, daß es ihm schon in einigen Jahren gelang das Repertoire gründlich zu erneuern. Neben wenigen klassizistischen und frühromantischen Werken ist die Zahl der historistischen Kompositionen überraschend groß. Zu finden sind Werke von Autoren des 16. und 17. Jahrhunderts (Gregor Aichinger, Gregorio Allegri, Claudio Casciolini, Bartholomeo Cordans, Antonio Lotti, Giovanni B. Martini, Giuseppe Ottavio Pitoni, Lodovico Viadana, Tomas Luis da Victoria, Giuseppe Olivieri, Antonio Scarlatti, Johann IV. von Portugal und Jacobus Gallus), so wie Werke von Epigonen aus den Reihen deutscher Cäcilianer. Der Prozess der almählichen Aussonderung der nach cäcilianischen Maßstäben nicht angemessenen Kompositionen, wurde bis zur Mitte der achtziger Jahre fortgesetzt, bis zum Zeitpunkt also, an welchem die historistische Vollendung ihren Höhepunkt erreichte. ${ }^{19}$

Foersters Bedeutung ist größer als die Rolle, die er bei der Erneuerung des Repertoires des Domes in Ljubljana hatte. Nach der Gründung des Cäcilianischen Vereins des Bistums Ljubljana wurde er zur zentralen Autotität der slowenischen cäcilianischen Bewegung. Als langjähriger Professor und Leiter der Orgelschule in Ljubljana

\footnotetext{
${ }^{16}$ Novice [Die Nachrichten], 23 (1865), Nr. 15, Seite 123.

${ }^{17}$ Ferdinand Vigele, "O cerkveni glasbi“ [Über die Kirchenmusik], in: Učiteljski tovariš 8 (1868), Nr. 8, Seite 121-124.

${ }_{10}^{18}$ Janez Zlatoust Pogačar, "Über Kirchenmusik", in: Triglav 4 (1869), Nr. 60, Seite 4-6.

${ }^{19}$ Anton Foerster, "Aufführungen des Domchores zu Laibach in Krain 1868-1876“, in: Musica sacra 9 (1876), Nr. 11, Seite 101-102.
} 
bildete er Generationen von Organisten aus, die die cäcilianischen Ideale aufs Land übertugen, als Redakteur der musikalischen Beilage der Zeitschrift Cerkveni glasbenik und Zensor von Kompositionen, diktierte er durch Jahrzehnte die Maßstäbe der Angemessenheit der für die Kirche geschriebenen Kompositionen. Er war einer der seltenen in Slowenien wirkenden Komponisten, die sich bei ihrer kompositorischen Arbeit den historistischen Vorbildern annäherte. In seinen Kompositionen auf lateinische Texte kann man Bemühungen des Autors entdecken, bestimmte Elemente der historischen Stile mit dem zeitgenössischen tonalen Chorsatz zu integrieren. Der Gebrauch des Falsobordon-Satzes und der Polifonie ist häufig, auffallend sind die ausgeglichene Formung der melodischen Linien und das vollkommene Ausbleiben der Chromatik. Sein Schaffen berührte auch die Kirchenmusik auf slowenische Texte. Obwohl sein Beitrag dieser Gattung verhältnismäßig bescheiden war, prägte er durch seine Tätigkeit als Redakteur des zentralen, in zehntausenden Exemplaren gedruckten slowenischen kirchlichen Liederbuches Cecilija, eben dieses Repertoire, welches sich am stärksten im slowenischen ethnischen Raum verbreitete. In Betracht genommen worden ist auch eine Anzahl von Kompositionen von Rihar, die teilweise korrigiert und neu harmonisiert wurden.

Foersters Wirken rief in slowenischen politischen Kreisen ein negatives Echo hervor. Im Jahre 1880 wurde er zum Opfer des gehässigsten satirischen Angriffs in der slowenischen Musikgeschichte. In der Zeitung Brencelj erschien hintereinander eine Reihe von Beiträgen, die die Grenzen einer noch annehmbaren Witzigkeit weit überschritten und schlugen stellenweise in sehr persönliche Angriffe auf den Charakter und die Persönlichkeit von Foerster um. Es kam zu einer langwierigen Polemik zwischen den Befürwortern der Cäcilianischen Bewegung und den Gegnern Foerster's, die ausgesprochen nationalistische und musikalisch reaktionäre Standpunkte verteidigten. Der Höhepunkt der Polemik war ein chauvinistischer Ausbruch von Jakob Alešovec, dem Redakteur der Zeitung Brencelj, der behauptete, daß wir Slowenen unsere eigene Musik und unsere eigene Komponisten haben, Foerster aber kann den Tschechen das Heil bringen. Die Polemik hatte keinen wesentlichen Einfluß auf Foerster's Tätigkeit, vergrößerte aber seine Abscheu gegen die Zusammenarbeit mit den weltlichen slowenischen Musikinstutionen, wodurch die allmählich erwachende slowenische Musik eines fähigen Mitarbeiters beraubt wurde. ${ }^{20}$

Aus diesem kurzen Überblick der slowenischen Kirchenmusik im 19. Jahrhundert ist deutlich genug zu entnehmen, daß ihre Entwicklung, so wie anderswo in Europa, durch die Gegensetzlichkeiten des Neuen und des Alten gekennzeichnet wurde - zwischen der Kirchenmusik des späten 18. Jahrhunderts und ihren Epigonen und der historistischen Kirchenmusik, einer Frucht der geistigen Strömungen in

${ }^{20}$ Brencelj [Die Bremse] 11 (1879), Nr. 14; Brencelj 11 (1879), Nr. 23-24; Jakob Ale\{ovec, "Odgovor na Poslano Foersterjevega peresa" [Antwort auf das gesandte Brief von Foerster], Slovenec 8 (1880), 11; Slovenski narod [Die slowenische Nation] 13 (1880), 18; Brencelj 12 (1880), Nr. 1; "Drugo poslano" [Das Zweite gesandte], Slovenski narod 13 (1880, 36; "Tretje poslano" [Das Dritte gesandte], Slovenski narod 13 (1880), 42. 
MUZIKOLOŠKI ZBORNIK - MUSICOLOGICAL ANNUAL XL

der ersten Hälfte des 19. Jahrhunderts. Die erste wird in den spezifischen kulturellsozialen Verhältnissen im slowenischen Raum durch die Tätigkeit von Gregor Rihar vertreten. Die slowenische Intelligenz, die in überwiegender Mehrheit noch immer von Geistlichen bäuerlicher Abstammung zusammengesetzt war, fasste sie als die ideale Verwirklichung der slowenischen nationalen Kirchenmusik auf. So gewann sie eine Bedeutung, die wesentlich ihren musikalischen Wert übertraf. Bedeutungslos blieb die Tatsache, daß sich die Melodien vor Rihar an verschiedene Quellen anlehnen, vom italienischen Belcanto bis zu Volksliedern des ostalpenländischen Raumes, die sonstige musikalische Struktur seiner Werke war aber in der Mitte des 19. Jahrhunderts schon vollkommen anachronistisch. In der slowenischen Musikkultur hatte dieses Repertoire eine ähnliche Rolle, wie z.B. die klassizistische Musik der Wiener Klassiker in der kaiserlichen Hauptstadt. Sie war traditionell, beliebt, vor allem aber war sie ein nostalgisches Symbol einer Epoche, die im steigenden Rhythmus des Lebens und der politischen Spannungen im 19. Jahrhundert allmählich für immer verblasste. (Der Unterschied zwischen beiden, in Bezug auf Gattung und Qualität, ist vor allem in einem verschiedenartigen sozialen Querschnitt beider Milieus zu suchen. Während sich die Entwicklung der Kirchenmusik des späten 18. Jahrhunderts und der ersten Hälfte des 19. Jahrhunderts in Wien vor allem in höfischaristokratischen Kreisen verwirklichte, entwickelte sich die slowenische zumeist in Ruhrahlen Verhältnissen.)

Auf den Verlauf der Gegenüberstellung des Neuen und des Alten in der Kirchenmusik in Slowenien im 19. Jahrhundert übte auch die spezifische kulturelle und politische Lage der slowenischen Nation ihren Einfluß aus. Der Mangel an festen Fundamenten, auf welchen sie ihre nationale Identität hätten aufbauen könnten (klein an der Zahl, die Begrenztheit der slowenischen Sprache und der Kultur auf die niedrigsten sozialen Schichten; das Fehlen eines politischen Rahmens, der eine Identifikation mit einer politischen Formung ermöglichen würde; usw.) rief bei der slowenischen Intelligenz, klein an der Zahl, das Gefühl einer nationalen Gefährdung hervor. Unter solchen Zuständen war die Einführung neuer Ideen in der Kirchenmusik äußerst schwierig. Alles Neue im 19. Jahrhundert kam nach Slowenien aus der Fremde, daheim gab es keine großen urbane Zentren, in welchen musikalische Neuheiten entstehen oder wenigstens schnell Resonanz hätten finden können. Die Träger des Neuen waren größtenteils einzelne Musiker, meist Fremde, die in entwickelteren kulturellen Zentren ausgebildet wurden, die die dort allgemein eingebürgerten Ideen in die slowenische musikalische Praxis einzuführen versuchten. Der Widerstand auf den sie stießen, war deswegen in der Regel mit Ausbrüchen von Heimatliebe verbunden. Zumeist war das ein aufrichtiger Ausdruck der Befürchtung vor dem Verlust der nationalen Eigenständigkeit. Bei Einzelnen ist die Möglichkeit nicht auszuschließen, daß das nationale Pathos nur eine Maske der mangelnde Bereitschaft und des Unvermögens einer Konfrontation mit dem Neuen, das langsam auch in die entfernte österreichische Provinz drang, darstellte.

Wenn wir am Ende das Verhältnis zwischen dem europäischen Raum und der slowenischen Kirchenmusik im 19. Jahrhundert zu definieren versuchen, kommen wir zu zwei Feststellungen: 
1.Durch die Beobachtungen der Einflüße des mitteleuropäischen Raums auf die Entwicklung der slowenischen Kirchenmusik im 19. Jahrhundert kann festgestellt werden, daß nur ein Teil des geografischen Gebiets, welches wir gewöhnlich mit diesem Begriff kennzeichnen, einbezogen war. Kontakte und Parallelen in der Entwicklung sind nur mit anderen österreichischen Erbländern und der Tschechei festzustellen, reichen aber auch über die Grenzen der Habsburger Monarchie nach Süddeutschland, dem Ausgangspunkt des Historismus' und der Cäcilianischen Bewegung. Kontakte mit östlicher liegenden Ländern (z.B. Ungarn, Slowakei) gab es fast nicht, oder sie waren ausgesprochen einseitig (z.B. slowenische Organisten suchten Arbeit in Kroatien). In dieser Hinsicht erweist sich der mitteleuropäische Raum also nicht als einheitlicher, es kommt auch im 19. Jahrhundert - ähnlich wie öfters in vergangenen Zeiträumen - zu einer entschiedenen kulturellen Abgrenzung zwischen Österreich und Ungarn, die noch immer - einem gemeinsamen Herrscher und Staate zum Trotz - sogar stärker war als die Staatsgrenze zwischen Österreich und Bayern. Aus slowenischer Perspektive bilden den mitteleuropäischen kulturellen Raum vor allem Österreich, die Tschechei, Norditalien, weniger Ungarn, die Slowakei, Kroatien und die östlicher liegenden Länder.

2.Die Entwicklung der Kirchenmusik in Slowenien war eng mit den Entwicklungsströmen der benachbarten Regionen verbunden. Vorerst waren die Verbindungen persönlich. Nach Slowenien kamen fremde Schaffende und Ausführende der Kirchenmusik, viele slowenische Musiker bildeten und formten sich künstlerisch in Musikzentren der benachbarten Länder (Regensburg, Wien). Nach Slowenien verbreitete sich aus den Nachbarländern auch das Musikrepertoire, welches entscheidend das musikalische Bild der gesamten Kirchenmusik, die hier entstand (so auf lateinische, als auch auf slowenische Texte) beeinflußte. Alle damaligen Widerstreite zwischen den Befürwortern der "einheimischen" und "fremden" (im Grunde genommen der alten und der neuen) Kirchenmusik, können nicht die Tatsache vermindern, daß Rihar's Anlehnen an die Melodik der italienischen Oper, des deutschen Singspiels, des alpenländischen Jodelliedes nicht im größeren Maße spezifisch slowenisch (und weniger mitteleuropäisch) war, als das Cäcilianische Anlehnen an den Gregorianischen Choral oder an die vokale Polifonie des 16. Jahrhunderts. Die nationale Festlegung der einen oder der anderen ist nur auf Grund unmusikalischer (die Sprache des Textes), keinesfalls musikalischer Kriterien, möglich. Darum können wir die gesamte.slowenische Kirchenmusik des 19. Jahrhunderts, so die alte wie die neue, als "mitteleuropäisch" bezeichnen. Davon zeugt auch die Strömung des Repertoires in entgegengesetzter Richtung, die bis jetzt in der slowenischen musikalischen Geschitsschreibung oft übersehen wurde. Die slowenische Kirchenmusik erstattete auch selber ihren - dem Umfang nach entsprechenden - Beitrag der europäischen und "mitteleuropäischen" katholischen Kirchenmusik. Das bezeugen die Kompositionen slowenische cäcilianischer Komponisten im Katalog des Deutschen Cäcilianishen Vereins, Ausgaben bei deutschen und österreichischen Verläge und Aufführungen von Werken Anton Foerster's in Wien. 